\title{
Measuring Progress in Gender Equity in Australian Policing
}

\author{
TIM PRENZLER AND HENNESSEY HAYES*
}

\section{Introduction}

This paper reports on a survey of police agencies in Australia regarding key indicators of gender equity. The survey was designed to identify the nature of change in the last decade and to test the capacity of senior management to evaluate performance. Marked differences were found between agencies in achieving progress and these differences indicated that management policies strongly influenced outcomes. It was also apparent that a greater commitment is needed to comprehensive data collection in order to properly diagnose and remedy inequities.

\section{Background}

This study is focused on the status of women in Australia policing in terms of aggregate level data. That is, the concern is with numerical outcomes and the diagnostic potential of such an approach. The premise is that numerical gender equality is desirable across policing functions. This is assumed on social justice principles, in terms of the equal performance capacity of women, and with reference to a right of access to female police officers by female offenders and female victims of crime. In terms of pressing concerns about police behaviour, there is also an argument that may be considered regarding the likelihood that women police will be less confrontational in dealing with the public, and less prone to abuse their power (Brereton 1999). However, as a rationale for employing more women, this arguably will be less significant than equal employment opportunity (EEO) imperatives. There is also an assumption in this paper about the legitimacy of some forms of 'unequal treatment' or affirmative action to improve the position of groups, such as women, who have a history of marginalisation.

The research behind these premises is well established and therefore will not be developed here. Questions of equal treatment and affirmative action are covered in the general literature on social justice and equal opportunity law (e.g. Bacchi 1992; Runkle 1982; Thornton 1990), as well as in specific applications to policing (e.g, Jones 1986; Scutt 1988; Steel \& Lovrich 1987). Performance studies have supported an enhanced role for women in policing (e.g. Bloch \& Anderson 1974; CJC 1998), as has research into the impact of women on styles of police work and conduct (e.g. Braithwaite \& Brewer 1998; Grennan 1987; Kennedy \& Homant 1983; Waugh et al 1998). The issue of citizen attitudes toward women police has also been largely resolved in favour of equality (Koenig \& Juni 1981; Winnard 1986).

* School of Criminology, Griffith University, Brisbane. E-mail: T.Prenzler@mailbox.gu.edu.au. Thanks to Carol Ronken for research assistance, and to the two reviewers for helpful comments on this paper. 
It is important to emphasise, however, that where women police now benefit from equal opportunity law and policies, this is only a very recent phenomenon. Historically, in the Nineteenth Century, women were entirely excluded from the 'New Police' and its variants in countries such as Australia. For much of the Twentieth Century, women were allowed a place within mainstream policing only in the most limited functions and numbers. As formal equality was achieved incrementally from the $1960 \mathrm{~s}$, women who were integrated in larger numbers experienced significant problems of sexual harassment and informal discrimination in deployment and promotion (Brown 1998a; Heidensohn 1992). Even the most progressive modern police department carries a recent legacy of intense hostility to women with a residue of cultural bias (Sutton 1996). This can manifest itself in subtle forms of resistance, such as ostensibly job-related physical entry tests that discriminate against women (CJC 1998; Prenzler 1996) or in opportunities for discrimination in the discretionary veto powers held by senior officers over selection panel decisions (CJC 1998). The legacy of misogyny poses an ongoing threat that must be pre-empted with active strategies of support for women, including proper evaluation of achievements and threats.

A key text in the women police evaluation literature is Sandra Jones's book, Policewomen and Equality: Formal Policy $v$ Informal Practice, published in 1986. The study is organised around four key chapters: 'Entering the Police', 'Doing "the Job"', 'Expectations and Career Choices' and 'Getting On'. Jones identified intense sex discrimination in the English police departments that she studied, although lack of quantitative data limited the accuracy of the findings. In 1990, in the United States, Susan Martin published On the Move: The Status of Women in Policing. Both studies marked important milestones in the development of knowledge about women in policing, and provided useful models for ongoing evaluation. In similar terms to Jones, Martin (1990) organised her study around the key gateposts of a police career: recruitment, training, deployment, promotion and separation. This approach may seem obvious, but it had not been obvious to the thousands of US police departments with performance and reporting obligations under EEO legislation, and the study was also greatly hampered by lack of data. From what was available, Martin concluded that the legislation had considerably opened policing to women (more so than in the UK), but this occurred in the face of sharp resistance and only after adverse decisions against police in the courts. Sex discrimination cases initiated by aggrieved women were successful in striking down barriers such as unfair physical tests. Police were barred from terminating a woman's employment if she became pregnant, and many agencies became subject to affirmative action orders to remedy the discriminatory practices of the past.

Martin calculated the percentage of women in state and municipal police agencies in the US at less than ten percent, with recruitment at about twenty percent. The increase in the number of female officers overall was steady but extremely slow, partly because the gain from recruitment was offset by high resignation rates. Progress differed markedly between jurisdictions. Martin also noted that female application rates were low and selection rates were lowered by residual physical entry tests. She also found that women performed well in the job but were underrepresented in both general duties policing and specialist squads, and over-represented in administrative or community-service oriented work. Although women were grossly underrepresented in the higher ranks, it was not clear whether this was the result of discrimination or lack of applicants. Discrimination and harassment did appear to be factors in higher female resignation rates. 
Jones and Martin sought official personnel data to examine the relationship between males and females at each point of the police career path. Where inequalities were identified, they used surveys, interviews and other qualitative sources to probe for possible causes. The method was consistent with the emerging concept of 'problem oriented policing' developed by Herman Goldstein (1990). Goldstein promoted an information driven approach by police to reducing crime, arguing that research could be used to identify critical variables in a specific crime problem. From this baseline, interventions could be developed and tested for their impact. This 'situational prevention' (Clarke 1992) was applied by Jones and Martin at the diagnostic level to the internal police problem of sex discrimination. The method was recently given a more formal structure and rationale in terms of 'a problem oriented approach to preventing sex discrimination in policing' (Prenzler 1997). The scheme proposed that all police agencies collect basic statistics for men and women across all points of the police career on a routine basis. This would allow for diagnosis of possible problems, development of interventions, testing and modification.

The problem oriented model is consistent with increasing obligations to report compliance with equal opportunity law. In Australia in 1993, an exploratory study revealed that most of the eight police agencies did not collect adequate data on gender equity (Prenzler 1995). The information supplied yielded similar results to those obtained by Jones and Martin. There was a very slow increase in the number of women police. However, there were significant differences between jurisdictions. New South Wales, Queensland and the Australian Federal Police were recruiting a greater percentage of women than applied. For example, in New South Wales from 1991-93, women were $25 \%$ of applicants and $30 \%$ of recruits. Victoria and Western Australia, most notably, recruited less women than applied, due primarily to the impact of tough physical tests. A mixed picture emerged in other areas such as academy completion rates and separations. The study referred to the only empirical research on promotion up to that time (Victoria Police 1990), released under a freedom of information application, which indicated that women in the Victoria Police were not being promoted as expected - all things being equal. In 1997, progress in application of the problem oriented model was tested in terms of policy development in a review of police EEO management plans (Prenzler 1998). The results were again extremely variable. Almost all agencies had plans for statistical reporting but they varied enormously in scope and in diagnostic capacity. The majority included commitments to diverse measures to improve the position of women. These included such things as mentoring support programs, childcare assistance, women's advisory committees and targeted marketing campaigns. In terms of evaluation, on the positive side, most of the agencies had plans for surveys of officers on gender issues and collection of basic statistics about the number of female officers. A few had more sophisticated plans such as exit interviews, monitoring of complaints of discrimination, or evaluation of the effectiveness of marketing initiatives. Of course, the test of the plans lay in their implementation.

\section{Research Method}

The project reported here was designed to test application of the problem oriented model, and served as a follow up study to both the 1993 national review of women's status in Australian policing (Prenzler 1995) and the 1997 review of EEO management policies (Prenzler 1998). Police EEO management plans contained acknowledgements that information lagged behind policy. Nonetheless, expectations were that new computerised personnel systems would soon bring the two together. In February 1999, two years after the plans were collected, a request for comprehensive data was made to the eight main police agencies - the Australian Federal Police (which enforces Commonwealth law and provides 
community policing to the Australian Capital Territory), Tasmania, New South Wales, Western Australia, the Northern Territory, Victoria, South Australia and Queensland. Because the question of 'progress' involved consideration of change over time, data were sought for the period 1991 to 1998 . The information requested covered the following in terms of male and female numbers:

- sworn officers as a total, by rank and by deployment

- recruit applicants, recruits and academy graduates

- separations by reasons

- sexual harassment and discrimination complaints by type and form of resolution

- promotion applications and promotions, and transfer applications and transfers by area.

Systematic application of the problem oriented model would mean that no special efforts would be required to provide most of these data as they would be collected on a routine basis and combined in one publication or regular reports. The results would provide a good indication of progress in gender equity as well as evidence of agency commitment to implementing EEO requirements with an information driven approach. ${ }^{1}$

\section{Results}

Table 1 shows the response across data categories. No agency could supply all the data requested and most had to make special exertions for what was provided. Victoria was the only agency that refused to directly supply data. In response to a follow up request referring to Victoria's freedom of information legislation, supply of some data was proposed by the Human Resource Management Department for a fee of $\$ 980.00$ ! The researchers refused the offer on the basis that the Victoria Police should collect the information as a matter of course and are accountable to the public. Items 1 and 2 in Table 1 contained the most basic information about male and female numbers of officers in total and by rank. Most of this was supplied directly. The Victorian data were obtained from annual reports. Items 3-9 involved a degree of sophistication above basic male/female ratios and were given a score out of two. Zero was given where no useful data were provided. A score of one was for data showing male/female differences but without sufficient detail for adequate analysis. A score of two was awarded for data that permitted some diagnostic analysis. The highest possible score was 14 . The table shows the average score was three. The highest score was 10 by New South Wales.

1 A methodological note needs to be made here regarding the status of 'unsworn' women. These police employees are slowly gaining recognition as essential contributors to the policing function and deserving of research. The limited literature indicates unsworn women are only slightly less vulnerable to harassment than swom women (e.g. Brown 1998a). In terms of powers and functions, significant differences remain between sworn and unsworn members. Moves to integrate the two groups in personnel statistics may allow a falsely positive impression about female representation because unsworn women usually outnumber sworn women, but mainly in secretarial and lower level administrative positions. This paper is exclusively about swom officers, partly because of their more direct role in policing and partly to avoid the difficulties of managing data from eight jurisdictions across two further categories of employees. 
Table 1: Survey response data quality rating

\begin{tabular}{|l|c|c|c|c|c|c|c|c|}
\hline & AFP & Tas. & NSW & WA & NT & Vic. & SA & QId \\
\hline 1. Percent & $\checkmark$ & $\checkmark$ & $\checkmark$ & $\checkmark$ & $\checkmark$ & $\checkmark$ & $\checkmark$ & $\checkmark$ \\
\hline 2. Rank & $\checkmark$ & $\checkmark$ & $\checkmark$ & $\checkmark$ & $\checkmark$ & $\checkmark$ & $\checkmark$ & $\checkmark$ \\
\hline 3. Deployment & 0 & 0 & 1 & 0 & 0 & 0 & 0 & 0 \\
\hline 4. Applicants/ Recruits & 0 & 0 & 2 & 0 & 0 & 0 & 2 & 2 \\
\hline 5. Recruits/Graduates & 0 & 0 & 0 & 0 & 1 & 0 & 0 & 1 \\
\hline 6. Separations/Reasons & 0 & 0 & 2 & 1 & 1 & 0 & 0 & 1 \\
\hline 7. Harassment & 0 & 0 & 2 & 0 & 0 & 0 & 0 & 1 \\
\hline 8. Discrimination & 0 & 0 & 2 & 0 & 0 & 0 & 0 & 1 \\
\hline 9. Promotion & 0 & 0 & 1 & 0 & 0 & 0 & 0 & 1 \\
\hline Score out of 14 & 0 & 0 & 10 & 1 & 2 & 0 & 2 & 7 \\
\hline
\end{tabular}

The fragmented nature of the data meant it was difficult to form a national picture of the status of women in Australian policing or to make inter-jurisdictional comparisons beyond the basic elements of recruitment and numbers of sworn officers. Consequently, much of the reporting that follows is in the form of case studies that provide points of insight and indicative lessons for policy. (Variations in time periods were necessitated by the need for consistency with different agencies providing data for different periods.)

\section{National Trends}

Figure 1 shows the percentage of female officers and recruits in Australia from 1994 to 1998 (covering the most consistent data). The results support previous findings (Prenzler 1995) of a steady but slight increase in the number of female officers in the order of about $0.4 \%$ per annum, increasing from $13.7 \%$ in 1994 to $15.2 \%$ in 1998 (barely discernible on a graph). The increase is clearly being driven by the flow through of female recruits at around $30 \%$, with an increase from $27.5 \%$ in 1996 to $36.2 \%$ in 1998 .

\section{Figure 1: Female officers and recruits, Australia, 1994-98}

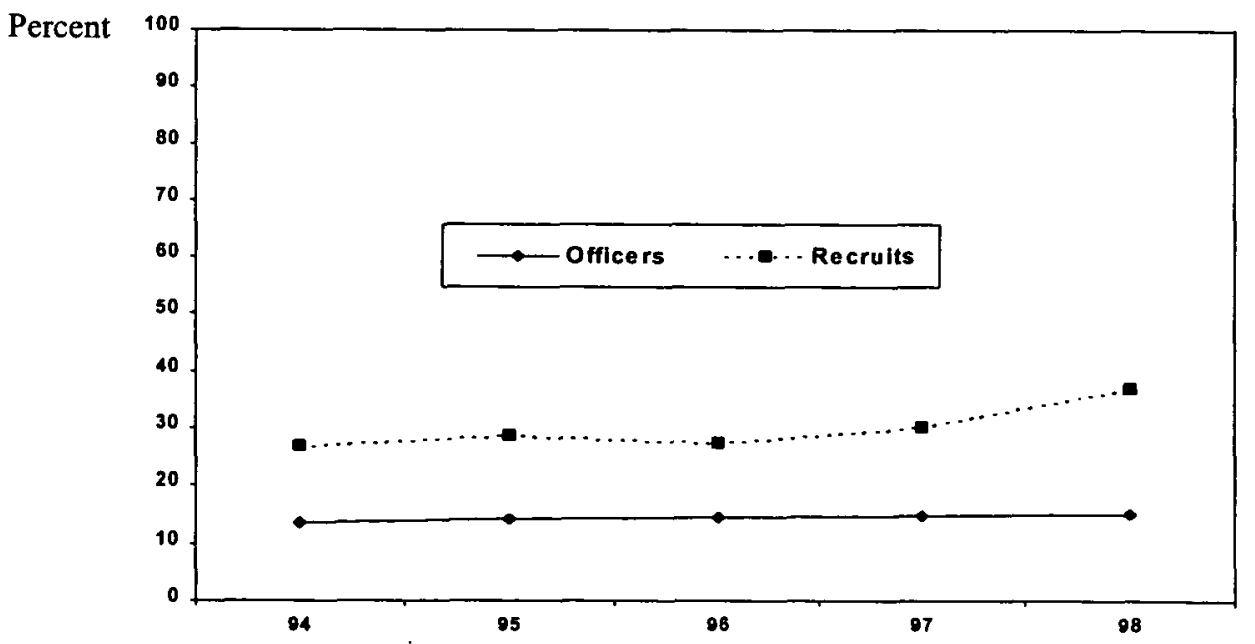


Table 2 reports the same data as shown in Figure 1, disaggregated by jurisdiction. It shows that the rate of progress is not consistent across agencies. Western Australia remained behind the other agencies, with a particularly poor recruitment result of $12.1 \%$ females in 1998 (following a sudden surge from 14.4\% in 1996 to $25.6 \%$ in 1997). Victoria is the only agency where the number of female officers declined in recent years - although the decline was extremely slight, from $13.4 \%$ in 1997 to $13.3 \%$ in 1998 . At $29.3 \%$, the number of recruits in Victoria in 1998 was in the middle range. The Northern Territory dropped from a very high percentage of $19.4 \%$ female officers in 1994 to $15.8 \%$ in 1996 with a resurgence to $17.7 \%$ in 1998 . New South Wales, South Australia and Queensland stood out with female recruitment rates of $42.6 \%, 36.0 \%$ and $34.8 \%$ respectively in 1998 , accounting for much of the increase in female recruits nationally from 1996.

Table 2: Percentages of female police and recruits by agency, Australia, 1994-98

\begin{tabular}{|l|l|l|l|l|l|l|l|l|l|l|}
\hline & \multicolumn{2}{|c|}{94} & \multicolumn{2}{c|}{95} & \multicolumn{2}{c|}{96} & \multicolumn{2}{c|}{97} & \multicolumn{2}{c|}{98} \\
\hline & O* & $\mathrm{R}^{* *}$ & $\mathrm{O}$ & $\mathrm{R}$ & $\mathrm{O}$ & $\mathrm{R}$ & $\mathrm{O}$ & $\mathrm{R}$ & $\mathrm{O}$ & $\mathrm{R}$ \\
\hline AFP & 16.7 & 34.6 & 17.2 & 42.1 & 18.6 & 20.0 & 18.7 & 50.0 & 19.1 & 30.0 \\
\hline Tas. & 11.8 & 31.2 & 12.5 & 40.7 & 14.8 & 30.0 & 15.1 & 26.3 & 16.0 & 28.3 \\
\hline NSW & 12.2 & 26.6 & 13.1 & 32.3 & 14.0 & 36.4 & 15.5 & 34.6 & 16.8 & 42.6 \\
\hline WA & 9.5 & 18.6 & 9.5 & 7.9 & 9.8 & 14.4 & 11.0 & 25.6 & 11.3 & 12.1 \\
\hline NT & 19.4 & 22.0 & 19.5 & 21.5 & 15.8 & - & 15.9 & 20.8 & 17.7 & 17.1 \\
\hline Vic & 13.4 & 19.0 & 13.8 & 23.6 & 13.8 & 19.2 & 13.4 & 25.2 & 13.3 & 29.3 \\
\hline SA & 14.6 & 37.7 & 14.7 & 36.3 & 17.2 & 44.4 & 15.4 & 34.6 & 16.6 & 36.0 \\
\hline Qld & 12.2 & 25.4 & 12.6 & 25.6 & 13.3 & 28.3 & 14.1 & 26.1 & 15.1 & 34.8 \\
\hline Total & 13.7 & $\mathbf{2 6 . 9}$ & $\mathbf{1 4 . 1}$ & $\mathbf{2 8 . 7}$ & $\mathbf{1 4 . 6}$ & $\mathbf{2 7 . 5}$ & $\mathbf{1 4 . 8}$ & $\mathbf{3 0 . 4}$ & $\mathbf{1 5 . 2}$ & $\mathbf{3 6 . 2}$ \\
\hline
\end{tabular}

* Officer. ${ }^{* *}$ Recruit.

The diversity of trends is illustrated in Figure 2 comparing the more salient cases: sworn officers in New South Wales (with the highest increase of $4.6 \%$ for the period 1994-98), the Northern Territory (which experienced the greatest reduction overall of $1.7 \%$ ), and Victoria (which experienced virtually no change at $-0.1 \%$ ). 
Figure 2: Female officers, NSW, Victoria and Northern Territory, 1994-98

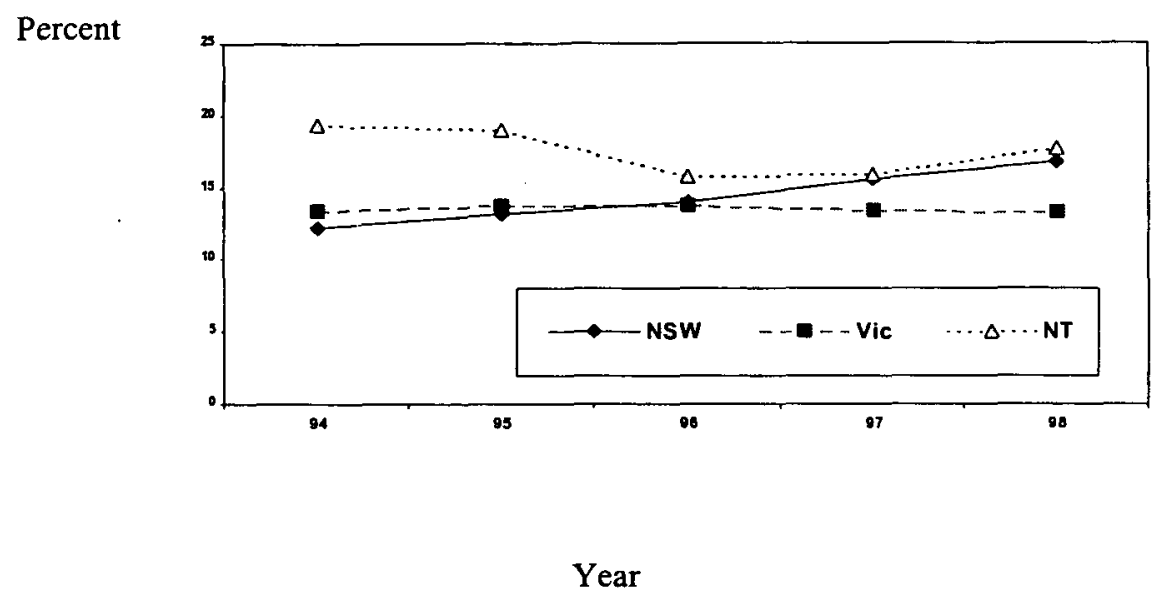

\section{Case Studies}

\section{Deployment}

No useful data were provided on deployment. The request was for male/female numbers in 'different sections and specialist units'. The only data supplied coming close to this was from New South Wales. However, these data included regions and did not cover all officers by function.

\section{Applicants/Recruits}

Only New South Wales, South Australia and Queensland provided data on applicants and recruits. New South Wales had a new system whereby applicants first apply to a universitybased course and then to the Service after completion. However, it would appear that the tertiary study requirement, together with a marketing campaign focused on women, produced the best result in terms of women making up $42.6 \%$ of beginning constables 'recruits' - in 1998 (Nixon 1999). (This might be compared with a figure of $42.3 \%$ female 'applicants' to the tertiary training program for a roughly comparable period.) Figure three shows that women in South Australia were recruited in numbers approximating their rate of application. However, the lack of data from the majority of jurisdictions makes it difficult to assess gender equity in recruitement across or between jurisdictions. 


\section{Figure 3: Female recruits and applicants, South Australia, 1991-98}

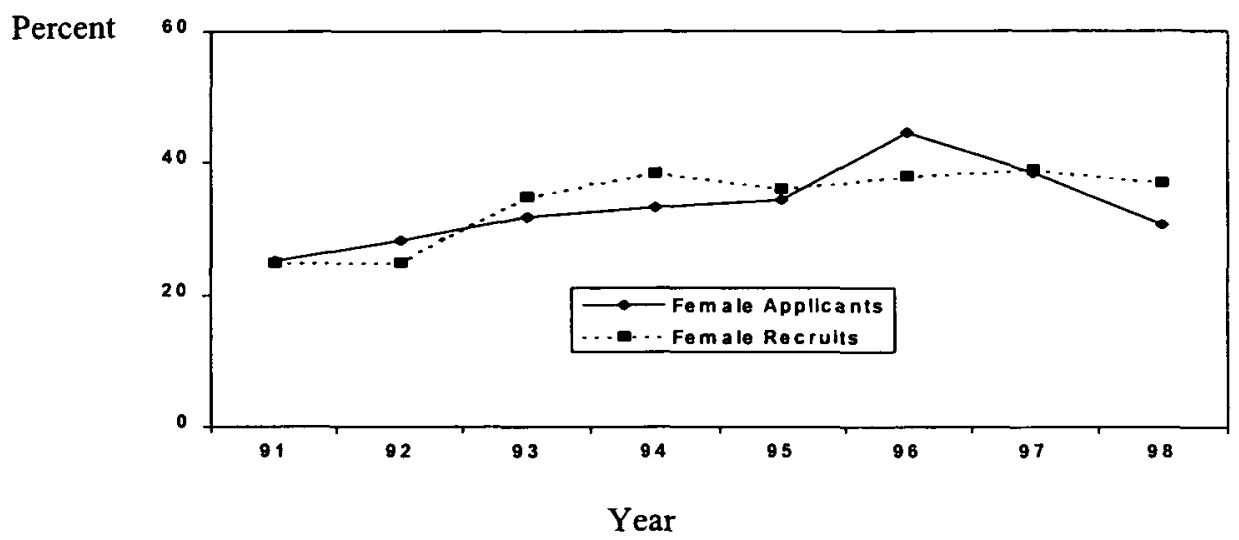

Queensland provides an interesting example of counteracting policies in recruitment. Figure 4 compares applicants and recruits, with two sets of figures for recruits. The first (top line) is recruits obtained through the normal selection system. This shows that for most of the period covered, women were recruited at a higher rate than applied. However, the second set of figures for recruits (bottom line) combines these mainstream recruits with 'rejoiners', recruited primarily from serving officers in other states. This alternative entry was introduced in 1994 to reduce training costs and reduce the large number of trainee constables at the front line. One of the unintended consequences was to reduce the total percentage of all women 'recruits' (combined 'recruits' and 'rejoiners'). The other point to note in the Queensland data is the impact of an obstacle course test on applicants introduced in 1994 and then modified because of the negative impact on women. For an analysis of these changes see Prenzler (1996).

\section{Figure 4: Female applicants and recruits*, Queensland, 1991-98}

Percent

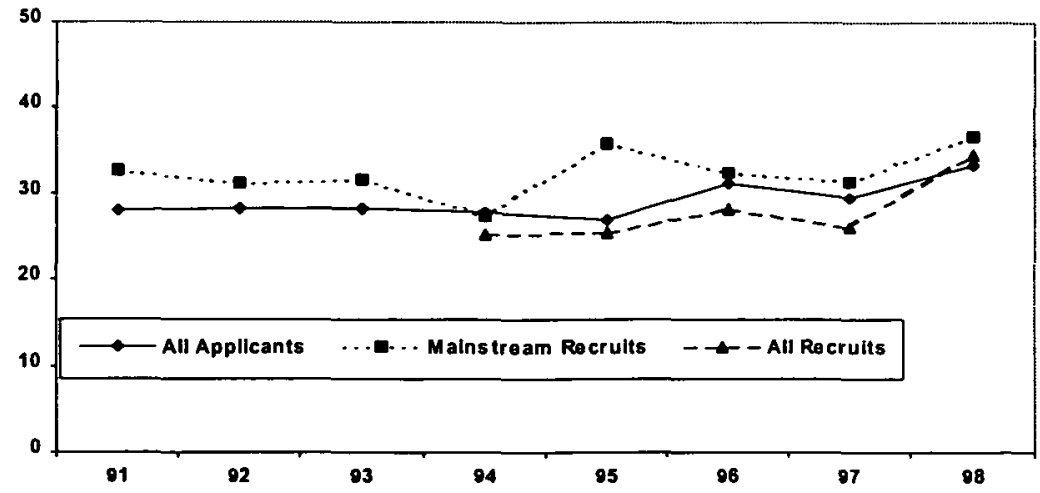

* 'All Recruits' includes 'rejoiners'. Rejoiners are former Queensland police or police from other jurisdictions who undergo a fast track entry process and training program. 


\section{Recruits/Graduates}

Only New South Wales, South Australia and Queensland provided data on recruits and academy graduates (note the above difference for NSW). The results were all similar in showing no apparant problem with attrition of women from the academy in these agencies. Figure five, for Queensland, is typical of this result, showing that women graduated from the academy at approximately the same rate at which they were recruited.

Figure 5: Female recruits and Academy graduates, Queenland, 1992-98

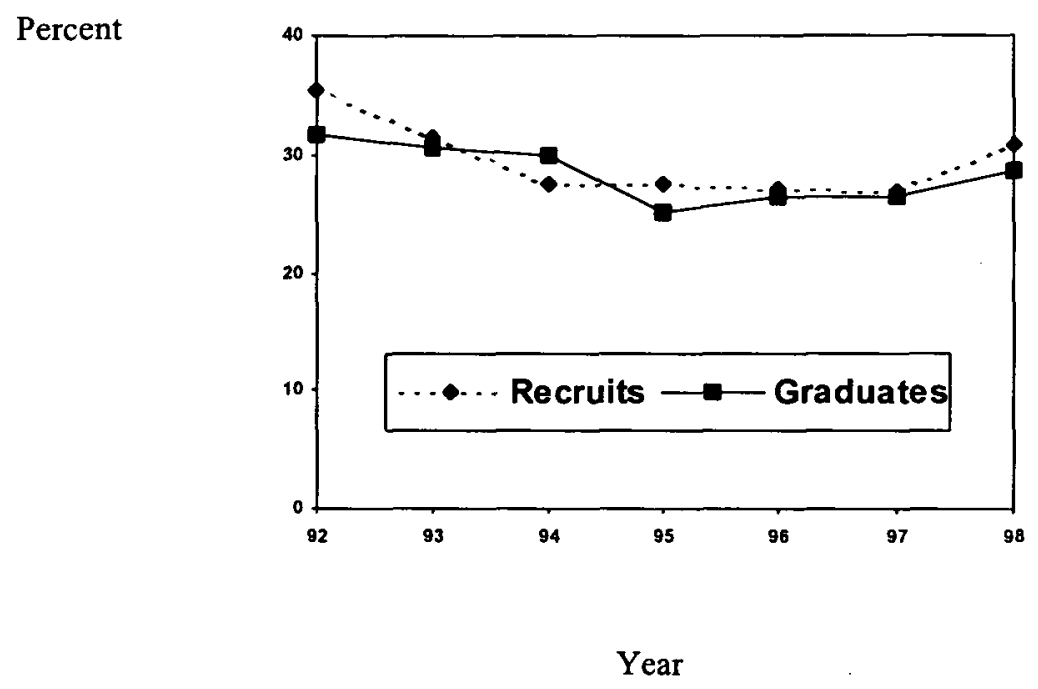

\section{Separations/Reasons}

Data on separations were supplied by the Northern Territory, Western Australia, Queensland and New South Wales. The data suggest that in these agencies women were separating in numbers roughly proportionate to their male colleagues. For example, in the period from 1994 to 1998 in the Northern Territory women averaged $17.6 \%$ of officers and $17.9 \%$ of separations. In WA the figures were $10.2 \%$ and $10.9 \%$. For Queensland they were $13.4 \%$ and $14.4 \%$; and for NSW, $14.3 \%$ and $12.8 \%$. However, a breakdown shows that male separations concentrated in the retirement area were offset by female separations by resignation. For example, in the Northern Territory, men were $100 \%$ of retirees; women were $20.7 \%$ of resignations (but $17.6 \%$ of total officers). In Western Australia, men were $98.8 \%$ of retirees; women were $15.3 \%$ of resignations (but $10.2 \%$ of total officers). In Queensland, men were $89.9 \%$ of retirees; women were $18.6 \%$ of resignations (but $13.4 \%$ of total officers). The most detailed data available from New South Wales (Figure 6) show that 'family/domestic' was a major factor in the female resignation rate where reasons for leaving were specified. Women also predominated in the large category of resignations for unspecified reasons. 


\section{Figure 6: Reasons for leaving, New South Wales, 1994-98}

Percent

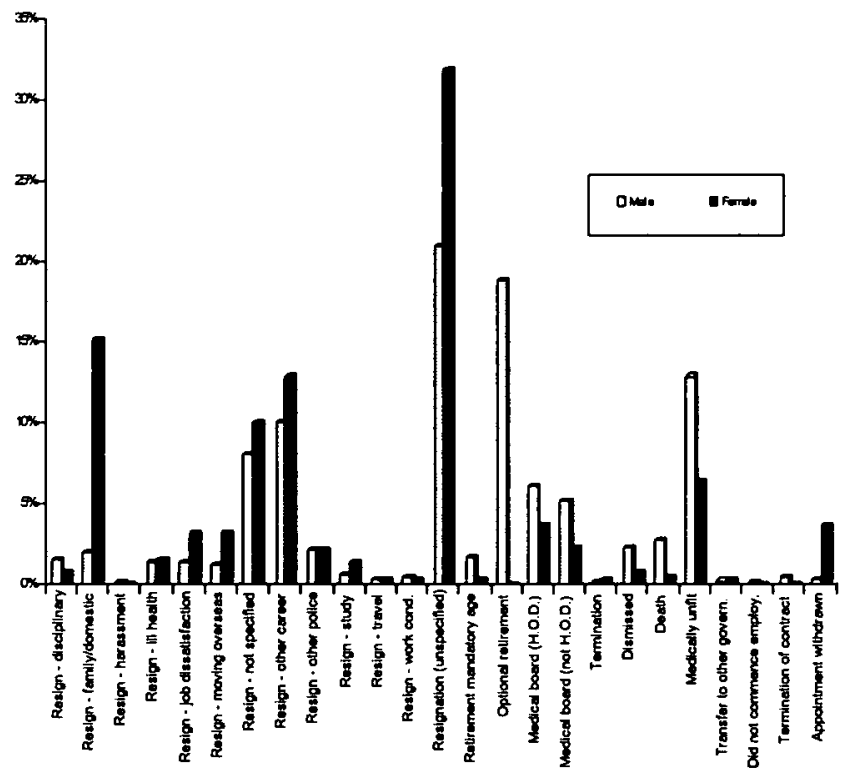

Reason for Separation

\section{Harassment and Discrimination}

Data also were sought on complaints and resolution of grievances. Only New South Wales and Queensland provided data. In New South Wales, for the period 1991-97, there was a small number of complaints of 'harassment/discrimination' (Figure 7), averaging 45 per annum, with women making up $90 \%$ of complainants. (The data were not disaggregated by sex of the purported source, but it is likely that most complaints concerned actions by men.) Complaints from women were resolved 'formally' in 36\% of cases and 'informally' in $64 \%$ of cases. (There was a sharp rise in the number of complaints in 1996 and a large fall in 1997.) The figures on harassment in Tables 3 and 4 for Queensland show a somewhat similar profile. The percentage of complaints from women regarding harassment by men fluctuated considerably in the short time period covered but averaged $81 \%$. 
Figure 7: Harassment/discrimination complaints, New South Wales, 1991-97

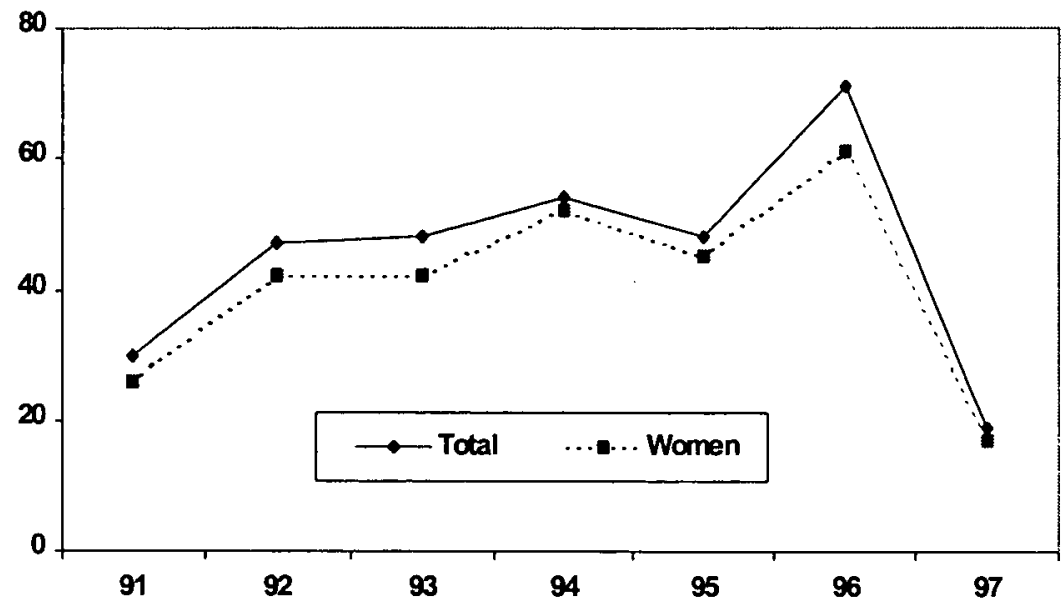

Table 3: Sexual harassment complaints, Queensland

\begin{tabular}{|c|l|l|l|l|l|}
\hline Year & Male to Female & Female to Female & Male to Male & Female to Male & Total \\
\hline 1996 & 20 & 0 & 1 & 0 & 21 \\
\hline 1997 & 10 & 4 & 3 & 3 & 20 \\
\hline 1998 & 35 & 2 & 1 & 1 & 39 \\
\hline Total & 65 & 6 & 5 & 4 & 80 \\
\hline Percent & 81.5 & 7.5 & 6.2 & 5.0 & 99.9 \\
\hline
\end{tabular}

Table 4: Sexual harrassment - form of resolution, Queensland

\begin{tabular}{|l|c|c|c|c|l|}
\hline Type & 1996 & 1997 & 1998 & Total & Percent \\
\hline $\begin{array}{l}\text { Conciliation/ } \\
\text { Mediation }\end{array}$ & 4 & 6 & 12 & 22 & 27.5 \\
\hline Advice Only & 11 & 9 & 16 & 36 & 45.0 \\
\hline Investigation & 2 & 1 & 7 & 3 & 3.7 \\
\hline ADC & 0 & 1 & 1 & 2 & 2.5 \\
\hline Other & 2 & 1 & 1 & 4 & 5.0 \\
\hline Transfer & 2 & 2 & 2 & 6 & 7.5 \\
\hline
\end{tabular}




\section{Promotion}

A request was made for the number of male and female applications for promotion and the numbers promoted. No agency provided these numbers. In lieu of this, data on rank were combined and compared over time to identify the rate of change. Ranks were collapsed into fewer categories because of different rank structures. The best data only allowed for a comparison over five years between 1993 and 1998 across Australia. These are shown at the national level in Figure 8. The results show that women were moving up the ranks, albeit extremely slowly. For Sergeant and above the average increase was $1.2 \%$. In the same period the number of sworn women increased by $2 \%$. However, it should be kept in mind that five years across combined ranks may not be sufficient to cover what might be considered a normal expectation of career progression. Something like 8-10 years at a rank could be considered more 'normal', at least up to the middle ranks.

\section{Figure 8: Percentages of females by rank, * Australia, 1993 and 1998}

Percent

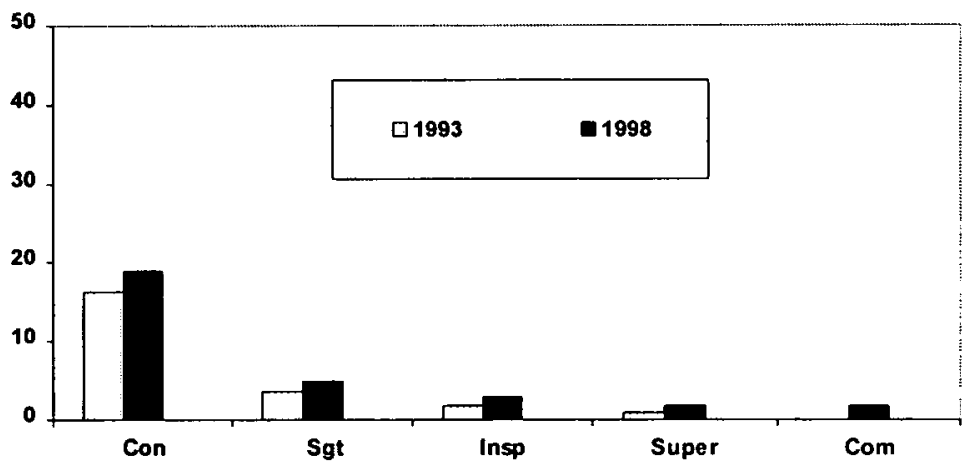

Year

* 'Constable' includes Senior Constable; 'Sergeant' includes Senior Sergeant;

'Superintendent' includes Commander; and 'Commissioner' includes Deputy and Assistant Commissioners.

Table 5 shows the same data broken down by jurisdiction. Again, Victoria and Western Australia - as well as Tasmania - showed only minimal changes. In these agencies there were no increases in the number women promoted to the ranks of Superintendent and above, and there were increases of only about $1 \%$ at the ranks of Sergeant and Inspector. New South Wales was well ahead of the other agencies with a $7.7 \%$ increase in the number of women promoted. While this figure was inflated by promotions of a few women in the very limited Commissioner category, this top level is likely to be the toughest to break into. 
Table 5: Change in percentage of women by rank, all jurisdictions, 1993 and 1998

\begin{tabular}{|l|c|c|c|c|c|c|c|c|c|}
\hline Rank & AFP & Tas. & NSW & WA & NT & Vic. & SA & QId & Total \\
\hline Commissioners & 0.0 & 0.0 & +25.0 & 0.0 & 0.0 & 0.0 & 0.0 & 0.0 & +1.7 \\
\hline Superintendents & +6.3 & 0.0 & -1.1 & 0.0 & +7.6 & 0.0 & +2.6 & +2.3 & +0.8 \\
\hline Inspectors & +1.2 & +2.1 & +1.7 & +1.0 & -0.4 & 0.0 & -2.0 & +1.3 & +1.0 \\
\hline Sergeants & 0.0 & +0.4 & +2.7 & +1.2 & +2.7 & +1.6 & +0.2 & +0.9 & +1.5 \\
\hline Constables & +2.9 & +1.1 & +5.3 & +1.7 & +3.9 & -1.8 & +2.2 & +4.5 & +2.6 \\
\hline Average & +3.4 & +1.2 & +6.7 & +1.3 & +3.5 & -0.2 & +0.75 & +2.25 & +1.52 \\
\hline
\end{tabular}

Figure 9 reports data supplied by New South Wales on the percentage of officers promoted who were women. These data are for progression from Sergeant to Deputy Commissioner and are compared with the percentage of female officers for the same years. The graph shows that women were promoted at a rate lower to their total presence in the Service, although the converging lines show that the female percentage of promotions was slowly catching up to the overall percentage of female officers. Table 6 reports the same data disaggregated by rank. The table shows that female representation in the Service and female promotions were concentrated at the lower ranks. This suggests that the comparatively lower female promotion rate overall may be explained in part by the relatively recent influx of women at the bottom of the hierarchy and the time lag involved in promotion. The higher resignation rate of women described above is also partially explanatory.

Figure 9: Comparison female promotion and female sworn officers, New South Wales, 1991-98

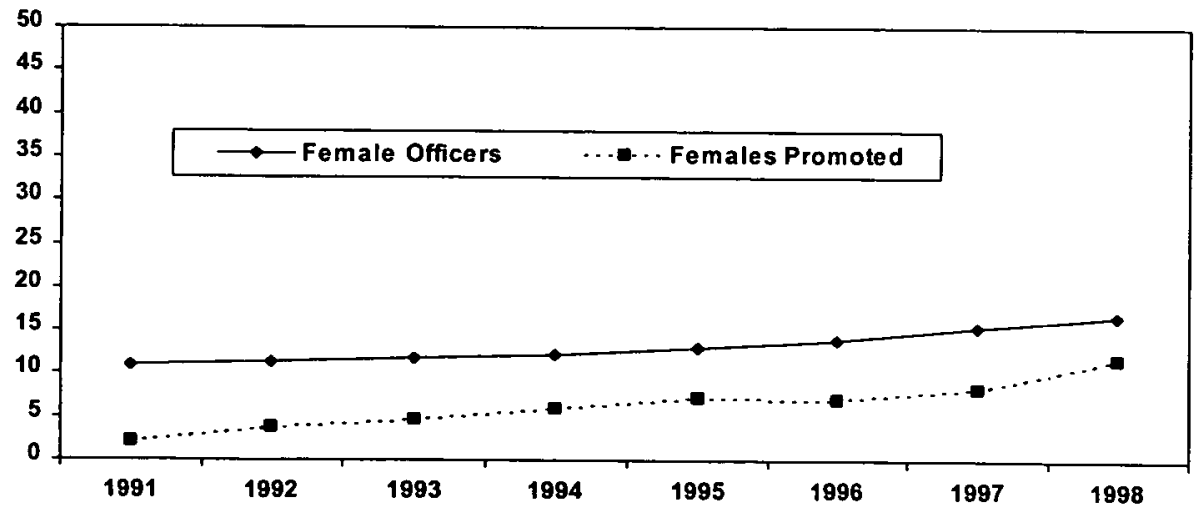


Table 6: Comparison of female promotions by rank* and total female sworn officers, New South Wales, 1991 and 1998

\begin{tabular}{|l|c|c|c|}
\hline Rank & 1992 & 1995 & 1998 \\
\hline Deputy Commissioner & - & - & - \\
\hline Assistant Commissioner & - & - & - \\
\hline Chief Superintendent & 0.0 & 0.0 & 0.0 \\
\hline Superintendent & 14.2 & 0.0 & 4.0 \\
\hline Chief Inspector & 0.0 & 9.0 & 0.0 \\
\hline Inspector & 0.0 & 1.7 & 0.0 \\
\hline Senior Sergeant & 0.0 & 6.4 & 22.2 \\
\hline Sergeant & 7.4 & 8.8 & 14.5 \\
\hline Total females promoted & 3.8 & 7.2 & 11.8 \\
\hline Total female oficers & 11.4 & 13.1 & 16.8 \\
\hline
\end{tabular}

* These are the ranks women were promoted to.

Table 7 reports data supplied by Queensland in a limited form. It shows the percentage of females combined for both promotion applications and lateral transfers, indicating that women were succeeding in their applications at a rate comparable to men. Overall, women were $10 \%$ of applicants and they constituted $11 \%$ of those promoted. However, because numbers were not supplied and significance tests could not be conducted, it is difficult to make judgements about specific outcomes, as in the case of the obvious failure of female applicants to be Plainclothes Constable.

Table 7: Female promotions and lateral transfers, Queensland, 1-7-97 to 30-6-98*

\begin{tabular}{|l|c|c|c|}
\hline Rank & \%F Applicants & \%F Selected & \% Difference \\
\hline Constable & 22.29 & 20.00 & -2.29 \\
\hline Plainclothes Constable & 26.09 & 0.00 & -26.09 \\
\hline Senior Constable & 12.09 & 19.90 & +7.81 \\
\hline Plainclothes Senior Constable & 18.29 & 9.52 & -8.77 \\
\hline Detective Senior Constable & 19.72 & 24.24 & +4.52 \\
\hline Sergeant & 6.51 & 8.93 & +2.42 \\
\hline Plainclothes Sergeant & 2.56 & 25.00 & +22.44 \\
\hline Detective Senior Sergeant & 3.53 & 6.67 & +3.14 \\
\hline Senior Sergeant & 2.93 & 5.88 & +2.95 \\
\hline Detective Senior Sergeant & 4.06 & 0.00 & -4.06 \\
\hline Inspector & 2.44 & 6.25 & +3.81 \\
\hline Detective Inspector & 3.79 & 16.67 & +12.88 \\
\hline TOTAL & 10.35 & 11.9 & +1.55 \\
\hline
\end{tabular}

* Constable to Inspector only. 


\section{Discussion}

A major finding of this study is that police agencies are not collecting sufficient information to properly assess issues of gender equity across all aspects of a police career. Interventions to address problems could not be developed without proper diagnostic research. For example, we could ask the question: are women still concentrated in more traditional areas of female employment (such as juvenile aid and child abuse) and excluded from specialist squads and detective work? At present, no agency appears to be able to answer this question. Although there were no perfect scores for data quality, New South Wales and Queensland clearly stood out with scores of $10 / 14$ and $7 / 14$ respectively. All the other agencies scored very badly with scores of two or less. In some cases, such as Victoria, this was consistent with very limited EEO management plans (Prenzler 1998). In other cases, most notably Tasmania, textbook EEO management plans have not so far been matched with data production. The poor performance of the Australian Federal Police was also surprising, given its reputation for innovation in modern management principles such as the use of performance indicators (Palmer 1995). It may be the case that most police agencies respond well to legislative requirements for EEO management plans but that there is insufficient enforcement of reporting standards by EEO regulatory agencies (Grabosky \& Braithwaite 1986; Prenzler 1998). This results in a preponderance of the symbolic purposes of law (such as creating the appearance of a just regime) over instrumentalist purposes (such as real equality).

Despite this negative overall assessment, there were sufficient data available to make evaluations in some important areas. In recruitment and in the number of female officers, the available data show a very mixed performance. Although women remained in an extreme minority position, a few agencies stood out as high achievers in increasing numbers. Some other agencies were notable underachievers. If New South Wales can recruit women above the $40 \%$ mark, it is likely that other agencies could do the same if they chose to. Questions of promotion and retention are crucial to any assessment of the status of women in policing. However, given that recruitment is the initial gateway to a police career, recruitment must stand as a crucial indicator of agency commitment to EEO. In the 1993 study referred to, all eight police agencies provided data on male/female application and acceptance rates (Prenzler 1995). In 1998 only three agencies were willing or able to provide this most basic information; indicating a counter-trend against enhanced accountability. The literature on women police is very clear that both the attitudes of senior managers and specific programs make a difference in improving female representation in application rates and recruitment rates (Felkenes 1991; Hyams 1991). The 1993 Australian study showed that obstacle course physical entry tests were responsible for most of the attrition of female applicants, most notably in Western Australia, and it appears unlikely that this has changed. The applicant/recruit data reported here for South Australia supports the view that a basic set of non-discriminatory procedures will produce parity in rates. The 1993 study also showed that New South Wales and Queensland, in a five year period, had moved from recruiting less women than applied to recruiting more, as a result of deliberate changes in policy. The effects are being sustained, but with some diminution in recruitment in Queensland due to the introduction of a program focused on rejoiners, most of whom are men.

In assessing equity in promotion, much more information is also needed before any reliable judgement could be made of possible discrimination or lack of appropriate progression. The analysis conducted in this study showed clearly that women were progressing up the ranks. The rate of progression has been extremely slow, but it is not possible, at the aggregate level, to confidently claim there is systemic discrimination. 
Possibly the best way to assess equity in promotion would be to first establish a norm for career progression - e.g. an average of eight years at each rank - then collect data on the number of male and female applicants and the number of successful applicants. This process allows a nominally qualified pool to be compared with actual applications and promotions. Where discrepancies are identified, further research could be used to probe causes and develop interventions. For example, it may be found that nominally eligible women are not applying for promotion at the same rate as men. A follow-up survey may show that women lack the necessary in-service training qualifications or experience, and therefore anticipate failure. This deficit could be addressed by a program to encourage women into in-service courses and facilitate more diverse work experience. Whatever the findings might be, the point of the exercise is to find the limits of management responsibility and trial supportive strategies wherever possible.

Only New South Wales and Queensland supplied data on complaints of harassment or discrimination. The Queensland data show that complaints from women about harassment by men predominated and that non-punitive conciliatory forms of response were favoured. (From a diagnostic perspective, the sudden rise and fall in complaints in New South Wales requires investigation.) In retrospect, data also should have been sought regarding satisfaction with outcomes. Both data sets show that some women had sufficient confidence in the system to come forward and make a complaint. Research suggests, however, that about $80 \%$ of women police in countries such as Australia claim to have experienced some form of harassment or discrimination (Brown 1998b). In Sutton's (1996) survey of women police in New South Wales, experience of sexual harassment was reported by $54 \%$ of female respondents with two years or less service. These experiences are typically underreported, and questions remain about the effectiveness of grievance procedures.

Although very limited in their scope, data on separations suggest that there is a partial 'revolving door' process occurring with women dropping out from their careers because of family commitments or other reasons, many of which are unknown. To address this, more attention might need to be given to retention policies such as flexible employment and rejoining options. In facilitating action it would also be useful to see estimates of financial losses incurred from sex discrimination by way of staff attrition, counselling, compensation payments and other costs.

In responding to EEO imperatives in police human resource management, it is clear that the laggards are well overdue to catch up with the advance guard. There is some evidence of this starting to occur in Victoria as a result of influences external to the Police Force. In 1998 a female officer was awarded $\$ 125,000$ damages by the State Anti-Discrimination Tribunal. This, and similar cases, galvanised a group of women activists to form 'Operation Womenforce'. The group began a publicity campaign 'to combat the perceived institutionalised harassment, neglect and negation of women police in Victoria' (The Journal 1998:11). In February 1999, Commissioner Comrie was obliged to declare that the Force had not done enough to remove discrimination and launched an equity program to 'catch up with community standards' (Towers 1999:3). In recruitment, there are no secrets about how to do this: remove obstacle course tests, target women in marketing, raise the standard of education, and ensure that selection panels have clear objective criteria and include female members. If necessary, introduce pre-application classes in policing and in application procedures (Felkenes 1991). The Victorian Commissioner's statement is encouraging. Nonetheless, one should remain suspicious of police declarations of reform. This case study of women police supports the observations of police scholars that police are adept at evading genuine accountability and of maintaining their operational independence 
(Palmer 1999). The problem is exacerbated by the passivity, not just of governments, but of regulatory bodies such as EEO agencies (Grabosky \& Braithwaite 1986; Prenzler 1996).

\section{Conclusion}

This study has shown that most police managers are not collecting sufficient data to adequately assess gender equity across all dimensions of their organisations. This in itself is an indicator of the inadequacy of management commitment to EEO. There appears to be a correlation between data collection and performance in that - generally speaking - the agencies that supplied the best data also showed the most progress. There were sufficient data on some key indicators, such as recruitment, to show this was not just an artefact of differences in the amount of data supplied. Ignorance serves its masters well. If problems are not identified, accountability need not follow. Given the fact that there has been little progress in the 1990s by the majority of police managers in addressing equity issues in demonstrable forms, it falls to outside bodies to take responsibility. These include police ministers and parliamentarians, government anti-discrimination and EEO agencies, police oversight bodies, and women's lobby groups. There is little prospect of reform unless these groups raise performance expectations and standards of reporting.

\section{REFERENCES}

Bacchi, C (1992) 'Do Women Need Equal Treatment or Different Treatment?', Australian Journal of Law and Society, vol 8, no 1, pp 80-94.

Bloch, P \& Anderson, D (1974) Policewomen on Patrol: Final Report, Police Foundation, Washington DC.

Braithwaite, H \& Brewer, N (1998) 'Differences in the Conflict Resolution Tactics of Male and Female Officers', International Journal of Police Science and Management, vol 1, no 3 , pp 276-87.

Brereton, D (1999) 'Do Women Police Differently? Implications for Police-Community Relations', paper presented to the Second Australasian Women and Policing Conference, 7-9 July, Brisbane.

Brown, J (1998a) 'Aspects of Discriminatory Treatment of Women Police Officers Serving in Forces in England and Wales', British Journal of Criminology, vol 38, no 2, pp 265-282.

Brown, J (1998b) 'Comparing Charges: The Experience of Discrimination and Harassment Among Women Police Officers Serving in Australia, the British Isles and the United States of America', International Journal of Police Science and Management, vol 1, no 3, pp 227. 40.

CJC (1998) Police for the Future: Review of Recruitment and Selection for the Queensland Police Service, Criminal Justice Commission, Brisbane.

Clarke, R (1992) Situational Crime Prevention: Successful Case Studies, Harrow and Heston, New York.

Felkenes, G (1991) 'Affirmative Action in the Los Angeles Police Department', Criminal Justice Research Bulletin, vol 6, no 4, pp 1-9. 
Goldstein, H (1990) Problem-Oriented Policing, McGraw-Hill, New York.

Grabosky, P \& Braithwaite, J (1986) Of Manners Gentle: Enforcement Strategies of Australian Business Regulatory Agencies, Oxford University Press, Melbourne.

Grennan, S (1987) 'Findings on the Role of Officer Gender in Violent Encounters with Citizens', Journal of Police Science and Administration, vol 15, no 1, pp 78-85.

Heidensohn, F (1992) Women in Control? The Role of Women in Law Enforcement, Clarendon, Oxford.

Hyams, M (1991) 'Recruitment, Selection and Retention: A Matter of Commitment', The Police Chief, September, pp 24-27.

Jones, S (1986) Policewomen and Equality, Macmillan, Houndmills Hampshire.

The Journal (1998) Official Publication of the Australasian Council of Women and Policing, no 1, summer.

Kennedy, D \& Homant, R (1983) 'Attitudes of Abused Women Toward Male and Female Police Officers', Criminal Justice and Behaviour, vol 10, December, pp 391-405.

Koenig, E \& Juni, S (1981) 'Attitudes Toward Policewomen: A Study of Interrelationships and Determinants', Journal of Police Science and Administration, vol 9, no 4, pp 463-74.

Martin, S (1990) On the Move: the Status of Women in Policing, Police Foundation, Washington DC.

Nixon, C (1999) 'Panel of Commissioners/Representatives of Police Jurisdictions', Second Australasian Women and Policing Conference, 7-9 July, Brisbane.

Palmer, D (1999) “"Confronting Police Culture"” or "The Force is Still With You"? Making Sense of Contemporary Policing in Australia', International Journal of Police Science and Management, vol 1, no 4, pp 333-46.

Palmer, M (1995) 'AFP Develops a Human Resource Strategy for the Changing Times', Platypus: The Journal of the Australian Federal Police, no 48, pp 4-5.

Prenzler, T (1995) 'Equal Employment Opportunity and Policewomen in Australia', Australian and New Zealand Journal of Criminology', vol 28, no 3, pp 258-77.

Prenzler, T (1996) 'Rebuilding the Walls? The Impact of Police Pre-Entry Physical Ability Tests on Female Applicants', Current Issues in Criminal Justice, vol 7, no 3, pp 314-24.

Prenzler, T (1997) 'A Problem Oriented Approach to Preventing Sex Discrimination in Police Recruitment' Crime Prevention Studies, vol 7, pp 207-222.

Prenzler, T (1998) 'Gender Integration in Australian Policing: The Evolution of Management Responsibility', International Journal of Police Science and Management, vol 1, no 3, pp 241-59.

Runkle, G (1982) Ethics: An Examination of Contemporary Moral Problems, Holt, Rinehart \& Winston, New York. 
Scutt, J (1988) 'Women and the Police', in Freckelton, I \& Selby, H (eds) Police in Our Society, Butterworths, Sydney.

Steel, B \& Lovrich Jr, N (1987) 'Equality and Efficiency Tradeoffs in Affirmative Action - Real or Imagined? The Case of Women in Policing', The Social Science Journal, vol 24, no 1, pp 53-70.

Sutton, J (1996) 'Survey of New South Wales Policewomen', paper presented to the First Australasian Women in Policing Conference, 29-31 July, Sydney.

Thornton, M (1990), The Liberal Promise, Oxford University Press, Melbourne.

Towers, K (1999) 'Promise of Uniform Rights', The Australian, 5 February, p 3.

Victoria Police (1990) The Impact of Equal Opportunity on Policing in Victoria, Review and Evaluation Division, Research and Development Department, Melbourne.

Waugh, L, Ede, E \& Alley, A (1998) 'Police Culture, Women Police and Attitudes Towards Misconduct', International Journal of Police Science and Management, vol 1, no 3, pp 288300 .

Winnard, K (1986) 'Policewomen and the People They Serve', Police Chief, vol 53, no 8, pp 62-3. 